\title{
Sensorineural Hearing Loss
}

National Cancer Institute

\section{Source}

National Cancer Institute. Sensorineural Hearing Loss. NCI Thesaurus. Code C26739.

Hearing loss resulting from damage to the cochlea, auditory nerve and/or brainstem. 